\title{
INHIBITION OF BACTERIAL GROWTH OF STREPTOCOCO MITIS BASED ON A WATER SEED EXTRACT FROM MORINGA OLEIFERA
}

\begin{abstract}
David Osti Flores ${ }^{1}$, Francisco Javier Llamas Del Olmo ${ }^{2}$, Mario Alberto Palomares Rodríguez ${ }^{2}$, Ricardo Reyes Flores ${ }^{2}$, Carlos Alberto Luna Lara ${ }^{2}$, Héctor Téllez Jiménez ${ }^{2}$.
\end{abstract}

\author{
${ }^{1}$ Graduate in Dental Surgeon, M.D, of the Dentistry Faculty, Autonomous University of Tamaulipas. \\ ${ }^{2}$ Professor of the Dentistry Faculty, Autonomous University of Tamaulipas.
}

DOI: 10.46609/IJETSI.2020.v05i01.004 URL: https://doi.org/10.46609/IJETSI.2020.v05i01.004

\begin{abstract}
Brushing and flossing are the most used and accepted procedures, the "gold standard", to control bacterial plaque, but these mechanical methods have limitations. The purpose of this research was to determine the in vitro antibacterial effect of a mouthwash made with Moringa extract on Streptococcus mitis. Materials and methods: The sample consists of $74 \mathrm{ml}$ of water-based moringa extract on which the antimicrobial effect of $S$ mitis was analyzed by means of an implant in agar for 24 hours to determine a process of interruption of development of S. mitis. Results: A $5.8 \mathrm{~cm}$ bacterial growth inhibition halo of $S$. mitis was obtained with the use of the moringa aqueous extract against $6.6 \mathrm{~cm}$ of $0.12 \%$ chlorhexidine. Conclusion: the aqueous extract of Moringa Oleifera has an inhibition of bacterial growth with statistically favorable results, although to a lesser extent than chlorhexidine.
\end{abstract}

Keywords: bacterial plaque, moringa oleifera, streptococo mitis.

\section{INTRODUCTION}

Dental caries in dentistry can be prevented by mouthwash, toothbrushing, dentifrices or disinfectants. Mouthwashes have been used as a wound disinfectant, for the control of bacterial plaque and in periodontal diseases. Currently in the market there is a wide variety of mouthwashes for rinse application, mentioning among its ingredients, for example, those of phenolic composition, quaternary ammonium (1), herbal extracts, essential oils, halogen compounds among others (2).

There is evidence about the causal relationship in the presence of Streptococcus mitis in plaque and the progression of caries in humans. 


\section{International Journal of Engineering Technology and Scientific Innovation}

ISSN: 2456-1851

Volume: 05, Issue: 01 "January-February 2020"

Rogers (3) pointed out that the prevalence of "bad induction" of streptococcus on plaque can be greatly underestimated when samples are confined to certain areas, particularly in cario-active individuals.

The Moringa oleífera, is a perennial tree belonging to the Moringáceas family with 14 species hitherto known and recognized as fast-growing plants in a varied range of climatic conditions (4), which can grow from $3 \mathrm{~m}$ to $9 \mathrm{~m}$, with flowers and fruits within the first year. It is highly resistant to droughts, but voidly resistant to frost and susceptible to fracture when there is a windy climate (5). It is native to the sub-Himalayan and northwestern areas of India, Pakistan, Bangladesh and Afghanistan, is one of the most cultivated and widespread species to other regions in Southeast Asia, Africa, Arabia, the Caribbean Islands and South America (4). These species are characterized by their long pods that contain seeds, dark brown and round or triangular in shape when they obtain a full maturity, with the core delineated with a thin membrane with three paper wings (4).

The leaves are eaten as vegetables without reporting any side effects, so they are also consumed by infants in South India; The high content of beta-carotene helps prevent vitamin A deficiency, hypocholesterolemia, hypotensive, anti-atherosclerotic activities, and antioxidant activities with linoleic acids, alpha tocopherols and oils were found in the extract of its leaves. Other studies have shown the presence of vitamin $\mathrm{C}$, flavonoids, phenolic components, fatty acids, as well as omega 3 and 6, calcium and potassium, the seeds are high in carbohydrates and proteins at 33$60 \%$ of their weight in dry (6-7). The seed of Moringa oleífera Lam has been widely used as an alternative for the population in terms of water treatment to reduce turbidity and provide better quality water, making it more suitable for human consumption. For a few years, research on medicinal plants is no longer seen as folklore, but as a relevant scientific activity, since medicinal plants are a viable alternative in the development of new therapeutic techniques, in obtaining new bioactive molecules that They manifest themselves in different mechanisms of action. Within modern medicine, the study and application of lectins, a protein present in the moringa seed, which have a theoretical and teichoic acid bond of peptidoglycans and lipopolysaccharides in the cell walls presents a sum importance (8). Water-soluble moringa seed extract is very active in staphylococcus aureus, inhibiting its growth, probably due to the high level of peptidoglycan found in Staph. aureus in your cell wall. This peptidoglycan contains Nacetylglucosamine, which makes it a potential target for chitin-binding lectins such as WSMoL (Water-soluble moringa lectin). Therefore, the efficacy of moringa extract in aqueous solution for the inhibition of bacterial growth of Streptococcus Mitis, which is a gram positive, nonmobile bacterium, mesophilic bacteria, of the group of Streptococcos Viridans, is usually assumed in small chains and They are part of the normal flora that inhabits the human oral cavity and is commonly recognized as a primary dental pathogen in dental caries. This bacterium is 
International Journal of Engineering Technology and Scientific Innovation

ISSN: 2456-1851

Volume: 05, Issue: 01 "January-February 2020"

generally not pathogenic, but it can cause dental infections, strep throat and infective endocarditis in susceptible individuals (8).

\section{MATERIALS AND METHODS}

Obtaining the aqueous extract of Moringa seed.

All moringa samples were obtained from the organic plantation owned by the Hidalgo ranch located in the Ejido Guadalupe in the town of González Tamaulipas. Moringa seeds were cleaned and disinfected: they are first washed with water and liquid soap, and then disinfected with $99.9 \%$ methyl alcohol.

As a next step of the hand grinding result, $150 \mathrm{ml}$ of PISA® brand deionized distilled water are added on a Benchmark® H4000 Hotplate Stirrer US plug magnetic stirrer at $750 \mathrm{rpm}$ for 30 minutes. The resulting suspension was filtered through a paper filter, and the filtrate obtained by dripping from a gravity-sized glass (the seed extract) with a final amount of $74 \mathrm{ml}$.

Subsequently, a test subject with no existing pathological history that made it difficult to sample was chosen. You were given information about the study, obtaining the sample, purpose and other related topics of the study.

Instruction was given to attend his appointment in time and time with a mechanical and / or liquid oral hygiene abstinence of 24 hours, and he was asked to go on an empty stomach.

Identification and isolation of $S$. mitis

The study of the in vitro sample of a strain of $S$. Mitis bacteria is carried out in a laboratory with a closed and sterile environment, with a temperature specific to the growth of bacteria in Petri dishes. Using $0.12 \%$ Chlorhexidine as a starting parameter for inhibition in S. mitis.

At the LISTER laboratory facilities, the bacterial plaque sample was obtained from the occlusal surfaces of all molars, lingual and vestibular anterior teeth, present in the oral cavity with a sterile swab, collected from the portion distal from the occlusal face to the mesial with slight pressure, repeating the same exercise on all occlusal, lingual and vestibular faces of the anterior teeth. This surface was previously isolated with cotton rolls and without drying the dental surface by air; The sample obtained was placed in an Amies transport medium.

The samples were taken inside the clinical analysis laboratory facility of the LISTER laboratory to be analyzed and processed. These were processed to perform a striated culture on blood agar in Petri dishes. After 24 hours and at a temperature of $37^{\circ} \mathrm{C}$, colonies of S. mitis were identified respectively, which were isolated and processed. 
The box was coded with the patient's name. Two boxes of Petri were included with the blood agar culture medium. On them, $1 \mathrm{ml}$ of moringa extract was deposited, sterile water was placed on the next, and $1 \mathrm{ml}$ of $0.12 \%$ chlorhexidine was placed on the third. Whenever the cultures went through the incubation process, a Petri dish was included with the innocuous culture medium, in order to rule out contamination of the crops to be studied.

The sample and control plates were incubated at $37^{\circ} \mathrm{C}$ for 24 hours. After this time, the bacterial growth was evaluated by the method of bacterial growth halos and biochemical identification tests carried out by the VITEK 2 COMPACT, where the $S$. mitis growth halo was identified.

The size of the growth halo of $S$. mitis arable from the baseline sample was identified, as well as the inhibition of bacterial growth after using distilled water, moringa extract and chlorhexidine as designated agents.

The type of study that has been carried out in this research is a development, quantitative, observational, open, experimental, transversal.

To determine the number of elements that made up the final sample for the present study, it was intended that they meet all the conditions or characteristics in the application to three Petri dishes with the content of blood agar and S. Mitis for a period of 24 hours. it required that the sample be determined in such a way that it was as small as possible without sacrificing accuracy or precision, applying the bacterial growth variable in Petri dishes with reference.

\section{STASTICAL ANALYSIS}

The halo inhibition results were reported as means and standard deviations; more over to evaluate differences between the groups the student's t-test was used after testing the assumption of normal distribution using the Kolmogorov-Smirnov test. All the statiscal analyses were performed using the IBM Statics 23 software.

\section{RESULTS}

The presence of Streptococcus mitis and Streptococcus oralism is detected in the colonies present in the growth halos. Likewise, the average growth halos presented a length of $6.9+-0.9 \mathrm{~cm}$ in Petri dishes assigned to the study groups (Figure 1). 


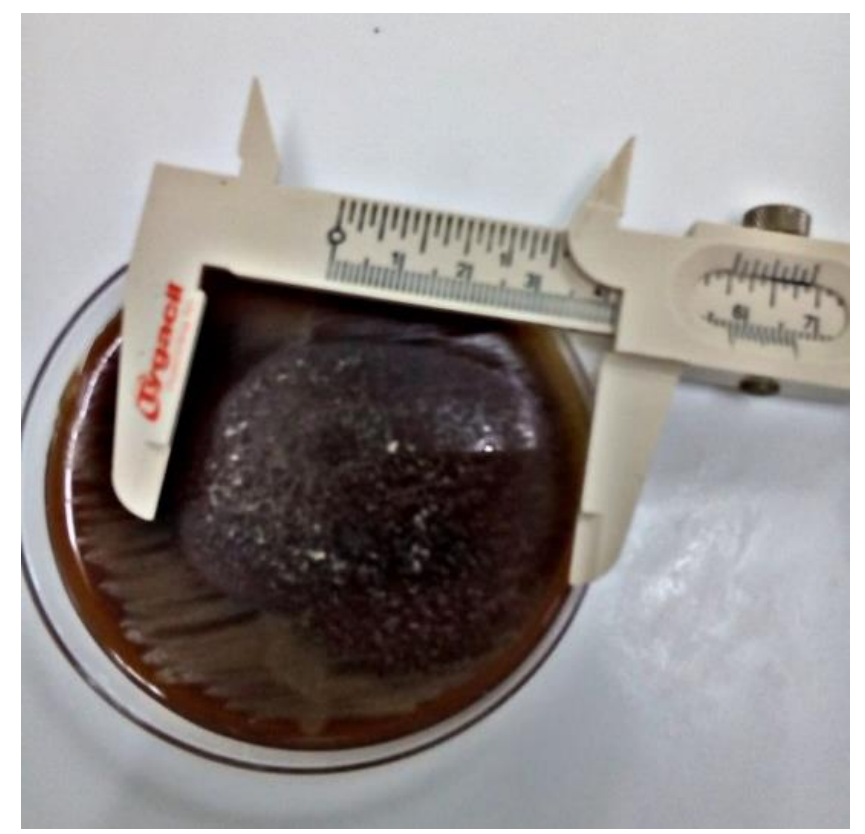

Figure 1: Bacterial growth inhibition with moringa extract.

The length of the halo of inhibition reported for each group was $6.6 \pm 0.5 \mathrm{~cm}$ for $0.12 \%$ chlorhexidine and $5.8 \pm 0.4 \mathrm{~cm}$ for the moringa-based aqueous extract. This difference was statistically significant $(\mathrm{p}<0.001)$ (Figure 2).

Samples not controlled reported favorable inhibition results.

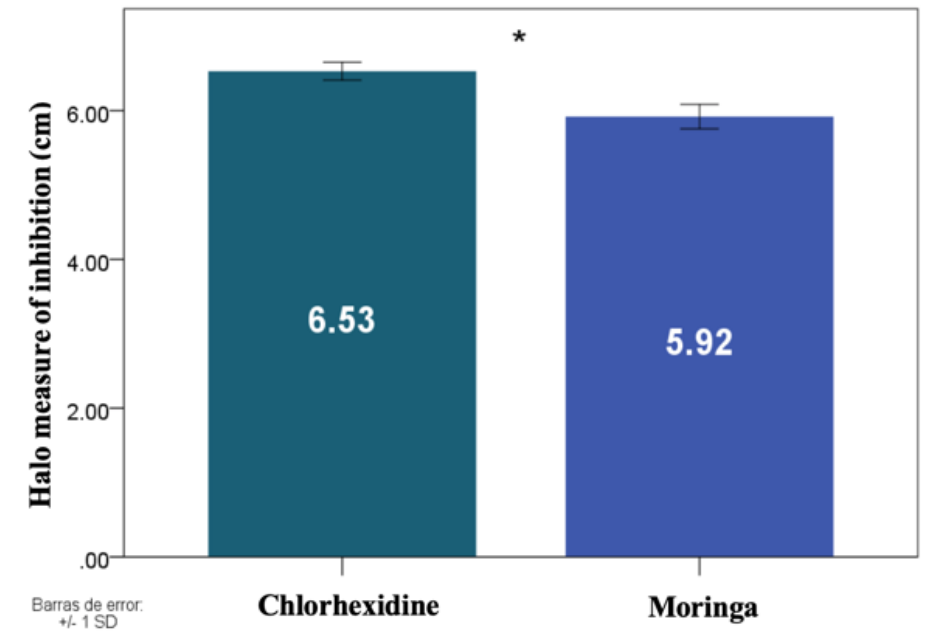

Figure 2: Comparison of bars representing the Mean in the Halo of inhibition. 


\section{DISCUSSION}

Significant differences were found regarding the average inhibition halos. Taking into account that the bioactive component of the mouthwash elaborated was Moringa Oleifera extract and from it were obtained inhibition halos lower than those determined in the complete use of chlorhexidine, but even on which it is determined that there was a bactericidal effect, the aqueous extract Moringa seed showed a bactericidal effect on Streptococcus mitis.

On the other hand, as can be seen in the present investigation, we worked with an aqueous extract of moringa seeds, although it is documented that the extraction of active ingredients is greater when alcohol is used as a solvent for the extraction solution. The difference in the results may be due to the fact that working with percentage concentrations is completely different from the volumetric concentrations in which if you can control the number of bioactive compounds present.

In addition, it must be considered that no matter how much one works with the same plant species, the results can be totally different because it has been shown that the concentration of active ingredients present in a plant is directly related to the habitat where it is cultivated and the type of soil among other factors (7). In the present investigation it was possible to demonstrate that the mouthwash made with $74 \mathrm{ml}$ of aqueous extract of moringa oleifera has antibacterial effect in vitro against Streptococcus mitis.

These results were verified through direct observation and through statistical analysis that determined a significant difference in the mean of the inhibition halos obtained in the control test carried out in Lister ${ }^{\circledR}$ Laboratory $^{1}$ and the experimental test, the results obtained in this investigation reveal that the extract of Moringa is only applicable in in vitro studies, and as a complementary artisanal and economic alternative for obtaining plaque control results in case you cannot access the commonly established medical treatments, if you wish to demonstrate its clinical relevance, you would have to replicate in in vivo studies in the cell line as a first phase and then in experimental animals and then in human subjects or in systems where the conditions may be the most similar to the oral cavity. The sequence of this will depend on the rational use given to these results, taking as reference for the elaboration of a new mouthwash or rinse, dentifrice, or clinical use as bacteriostatic in the carious cavity, thus highlighting its auxiliary use to the methods already determined, especially mechanics such as tooth brushing, without intending to replace any of them. Therefore, the present study serves as a basis for further expansion of knowledge about the use of this tree in the prevention and treatment of certain pathologies of the oral cavity. In this sense, the mouthwash made with aqueous extract of

${ }^{1}$ Local laboratory service. 
International Journal of Engineering Technology and Scientific Innovation

ISSN: 2456-1851

Volume: 05, Issue: 01 "January-February 2020"

moringa seed suggests being of important use as a complement in the control of certain oral pathogens.

\section{CONCLUSIONS}

Moringa extract has the ability to inhibit bacterial growth due to the high content of lectins that it has in its structure, so it affects the metabolism of the cell wall by limiting the assimilation of glycoproteins that the bacteria can obtain for its development.

Morifea Oleifera, eliminates the growth of the bacteriological process and fights $S$. Mitis with a $5.8 \mathrm{~cm}$ inhibition halo that stops the infection process and therefore caries remains controlled and / or eliminated. The extract of moringa in use of aqueous rinse has a growth inhibition in the bacterium Streptococcus Mitis and fights caries non-invasively in an in vitro sample. Chlorhexidine showed statistically favorable results compared to the use of aqueous moringa seed extract.

\section{REFERENCES}

1. Bergamo VZ, Donato RK, Nemitz MC, Acasigua GAX, Selukar BS, Lopes W, et al. Assessing an imidazolium salt's performance as antifungal agent on a mouthwash formulation. J Appl Microbiol. 2016; 121(6):1558-67.

2. Reich E, Brecx M, Netuschil L, Petersson LG. Mouthrinses and periodontal disease. Int Dent J. 2002; 52(5):346-52.

3. Rogers AH. The ecology of Streptococcus mutans in carious lesions and on caries free surfaces of the same tooth. Aust Dent J. 1973; 18(4):226-8.

4. Boukandoul S, Casal S, Cruz R, Pinho C, Zaidi F. Algerian Moringa oleifera whole seeds and kernels oils: Characterization, oxidative stability, and antioxidant capacity. Eur J Lipid Sci Technol, 2017; 119(10):1600410.

5. Lea M. Bioremediation of Turbid Surface Water Using Seed Extract from Moringa oleifera Lam. (Drumstick) tree. Curr Protoc Microbiol, 2010; Chapter 1: Unit1G2.

6. Fitriana WD, Ersam T, Shimizu K, Fatmawati S. Antioxidant Activity of Moringa oleifera Extracts. Indones J Chem, 2016; 16(3): 297-301.

7. González Garza NG, Chuc Koyoc JA, Torres Castillo JA, García Zambrano EA, Betancur Ancona D, Chel Guerrero L, et al. Biofunctional properties of bioactive peptide fractions from protein isolates of moringa seed (Moringa oleifera). J Food Sci Technol. 2017;54(13):4268-4276.

8. Ferreira RS, Napoleão TH, Santos AFS, Sá RA, Carneiro-da-Cunha MG, Morais MM, et al. Coagulant and antibacterial activities of the water-soluble seed lectin from Moringa oleifera. Lett Appl Microbiol, 2011; 53(2):186-92. 